\title{
Steel Concrete Composite Systems for Modular Construction of High-rise Buildings
}

\author{
J. Y. R. Liewa,b*, Z. Dai ${ }^{a}$ and Y. S. Chua ${ }^{a}$ \\ ${ }^{a}$ Department of Civil and Environmental Engineering, National University of Singapore, Singapore \\ ${ }^{b}$ College of Civil Engineering, Nanjing Tech University, Nanjing, China \\ *corresponding author, e-mail address: ceelyj@nus.edu.sg
}

\begin{abstract}
Modular construction has gained popularity and attention particularly in low-rise building lately due to its numerous advantages: faster construction speed, better quality control, reduction in work force and construction waste, etc. This innovative technology promotes off-site manufacturing of modular units and on-site assembly, improving the construction efficiency and productivity. However, modular construction is not commonly used in highrise buildings because of the joints' flexibility as well as manufacturing and construction tolerance, which have significant impact on the overall stability of the building. This paper highlights the existing challenges of modular construction of high-rise buildings and provide several options to address these challenges. Firstly, the weight of a module is constrained by the transportation and lifting crane capacities. For this reason, lightweight concrete is introduced together with structural steel section to form lightweight steelconcrete composite system to reduce the weight of the module without compromising the strength and stiffness. Secondly, to speed up the site assembly of modular units, special joints are developed to resist the forces due to gravity and horizontal loads. Fast and easy joining techniques with acceptable tolerance control are essential to ensure the structural integrity and stability of the building. Finally, the innovation for productivity can be maximized by implementing automation technologies in the manufacturing and construction of the modular units.
\end{abstract}

Keywords: Modular construction; Composite design; Lightweight concrete; Fast Joint; High-rise building.

\section{Introduction}

Conventional construction methods such as cast in-situ structural elements and brick walls are still widely used at present due to the financial feasibility of such construction methods with relatively low labor cost in some countries. This has been highlighted to be one of the factors which impedes the growth in construction productivity [1]. At the same time, the exploding population and the unprecedented urbanization call for more high-rise buildings. Coincidently, a good design practice of high-rise buildings is to embrace simplicity, standardization, repetition, and economy of scale. This renders the high-rise buildings intrinsically modular [2].
To overcome these challenges, modular construction has been encouraged in Singapore whereby building modules are constructed offsite before being assembled on-site to form a building. Prefabricated Prefinished Volumetric Construction (PPVC) is a specific type of modular construction where the internal elements of the module (walls, floors and ceilings etc.) are prefinished before the modules are assembled. With the advantages of higher construction speed, productivity and quality control, PPVC has been adopted in many sectors of the building industry, such as residences, hotels and hospitals by many countries over the last 20 years. In recent years, Singapore Building and Construction Authority (BCA) has also 
shown great effort to promote PPVC in local projects to achieve a productivity improvement in terms of construction time and manpower up to $50 \%$. Since 2014, the use of PPVC in selected public residential projects has been made mandatory [3]. The benefits of PPVC has been proven in the successful launching of pioneer PPVC projects in Singapore: (a) Crowne Plaza Hotel Extension, Changi Airport, and (b) NTU North Hill Residence Hall as shown in Fig. 1. It is reported that both projects have achieved time savings of up to 6 months and on-site manpower savings of up to $40 \%$. These projects give confidence to the industry, government, and general public on this new technology. Due to the supportive government, it is projected that by $2019,35 \%$ of newly launched housing board projects will be built using PPVC.

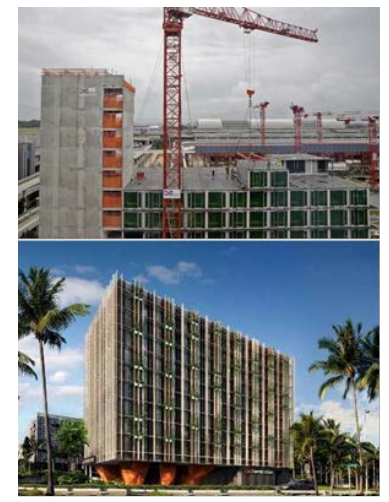

(a)

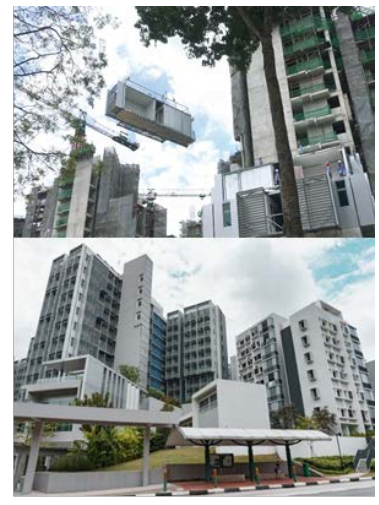

(b)
Fig. 1. Pioneer PPVC projects in Singapore (a) Crowne Plaza Hotel Ext @ Changi Airport, and (b) NTU North Hill Residence Hall.

PPVC concept appears to be compatible with high-rise building which encourages design standardization and repetition. Nonetheless, it is not so commonly used in high-rise buildings because of its novel structural form, joints' flexibility as well as manufacturing and construction tolerance, which have significant impact on the overall stability of the building. The continuity of the beam-column frame is uncertain and the reliance on lateral resisting system is essential especially for high-rise buildings, which are commonly found in Singapore. Therefore, this paper highlights the existing challenges of modular construction of high-rise buildings and provide several options to address these challenges.

\section{Modular construction as solution}

There are two types of PPVC module systems with different types of load path. Load-bearing wall module are commonly found in concrete building, whereby the concrete walls are used to transfer gravity loads to the foundation, as well as resisting the lateral loads as displayed in Fig. 2. On the other hand, Fig. 3 shows cornersupported module, which is generally made of steel or steel-concrete composite material, in which the gravity loads are transferred to edge beams to the columns and foundations. Generally, the weight of a steel modular unit is about 15 to 20 tonnes, which is relatively lighter than a concrete modular unit with weight of about 20 to 35 tonnes. Moreover, steel modular system has more flexibility in architectural design due to its open space frame and larger modular size. The construction speed of steel modular system is also faster as it commonly involves bolted connection whereas concrete modular system often requires in-situ grouted connection. Nonetheless, steel modular construction may experience durability issues that require additional measures to address issues realted to corrosion and fire. For these reasons, steel PPVC systems are commonly used in institutional and commercial buildings, whereby open space are necessary. On the other hand, concrete PPVC systems are preferable in residential buildings due to better durability and ease of inspection.
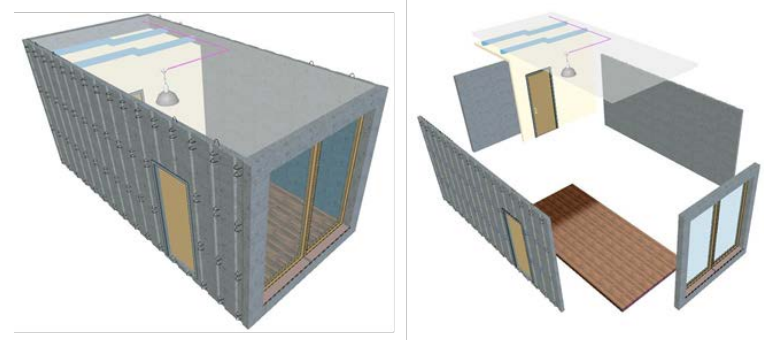

Fig. 2. Load bearing modular system.
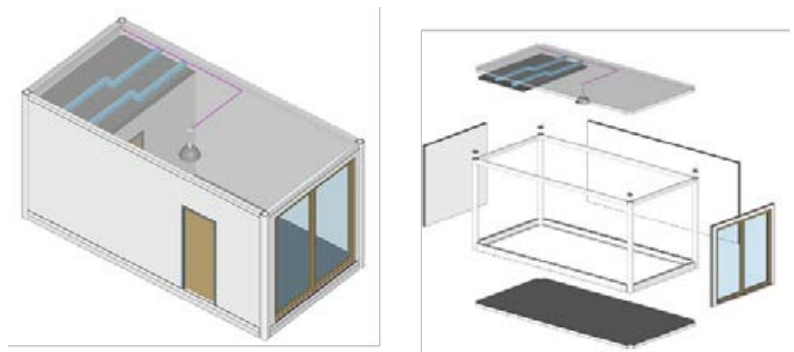

Fig. 3. Corner supported modular system. 


\section{Challenges in high-rise modular construction}

This paper focuses on steel modular construction because of its high potential in improving construction productivity and higher performance to weight ratio. There are many challenges in high-rise modular construction because the building is constructed by stacking up the modules, connecting them together using joints. Firstly, the weight and size of a module are constrained by the transportation and lifting capacities [4]. Furthermore, the joint design is critical to ensure the robustness and continuity of the structural modules with redundant load paths. As the modules are prefabricated off site and assembled on site, the manufacturing and construction tolerances are essential to prevent accumulative error during the module stack-up. To address these challenges, several options are discussed below.

\subsection{Lightweight modular unit}

Logistics for modules transportation from factory to site affects the maximum size and weight of each module design, which in turn affects the number of modules to complete the layout design. The size of a typical modular unit should be kept within the local authority's regulatory without requiring additional treatment such as police escort. For instance, Land and Traffic Authority in Singapore requires that the width of the module should be less than $3.4 \mathrm{~m}$ while the maximum height of the module is restrained to $4.2 \mathrm{~m}$ as depicted in Fig. 4 to avoid clashing with overhead bridges regulatory. Secondly, the lifting of modules during stacking and assembly also constrains the weight of a modular unit. According to local consultants, most PPVC projects in Singapore use lifting cranes with up to 20 tonnes capacity while only a few projects can reach 35 tonnes as the lifting crane price shoots up significantly when its capacity goes beyond 20 tonnes. Therefore, hoist weight and transportation size are critical challenges in PPVC.

Fig. 5 shows typical weight distribution in a steel modular unit [5]. It is observed that the two largest components that contribute to weight are floor material and steel weight. Thus, composite design can be used in PPVC in order to reduce the steel usage owing to increased stiffness of the system, thus composite slab and beam design is attempted for the replacement of existing steel structure in order to reduce floor weight and increase performance [6]. Other than reducing the weight, this design allows larger headroom in a PPVC unit. This is an important aspect in PPVC design because of its double slab system (e.g. floor and ceiling) that reduces the available headroom. The weight of a modules can be further reduced by using lightweight concrete in the slim floor system. Additionally, lightweight partition wall can be incorporated in the PPVC system because they are for non-structural purpose but require good acoustic and fire protection.

Hoisting weight can be further reduced by using composite design in column such as rectangular concrete-filled tubular column. This is due to weight of concrete cast-in situ is not included in hoisting weight and thus, by separating the infill concrete weight and steel weight, aim of reducing hoisting weight can be achieved.

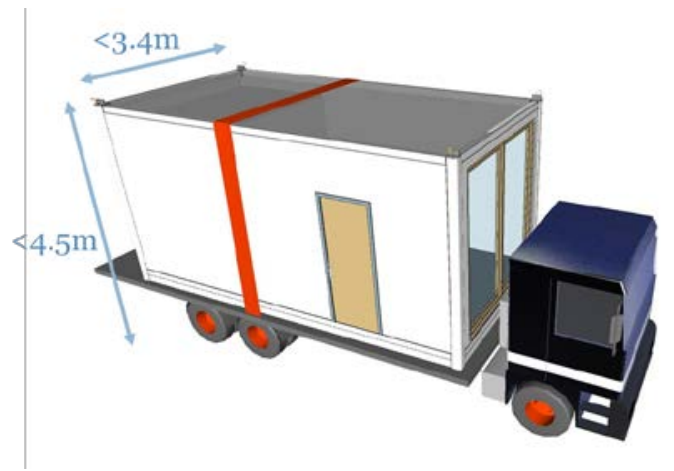

Fig. 4. PPVC module size limit due to transportation truck.

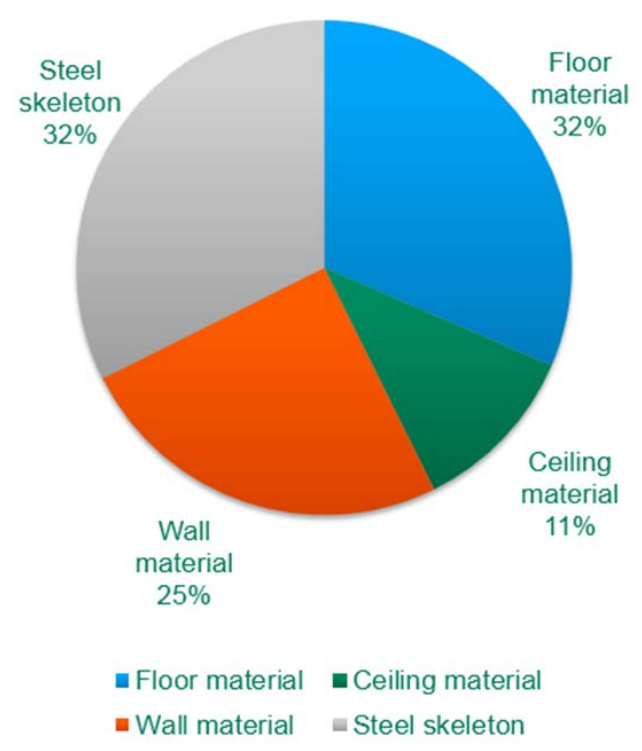

Fig. 5. Weight distribution in a steel modular unit [5]. 


\subsection{Fast-installed jointing techniques}

Joint design in modular construction aims for fast and easy installation yet able to provide sufficient resistance. As shown in Fig. 6, all the steel members are connected using welded connections within a steel module. Beam-tocolumn joints can usually be treated as rigid connection when full strength butt welds are used. Since there are no guidelines in designing such joints, numerical analysis and experiments are usually needed to confirm its rigidity [7]. Corner-supported modules are connected with adjacent modules via beams and columns as shown in Fig. 6. Just like conventional frame structures, joints of steel PPVC buildings can be classified as corner joints J1, perimeter joints $\mathrm{J} 2$, and internal joints J3. Different joints have different connection details and thus have different structural performances and loading conditions.
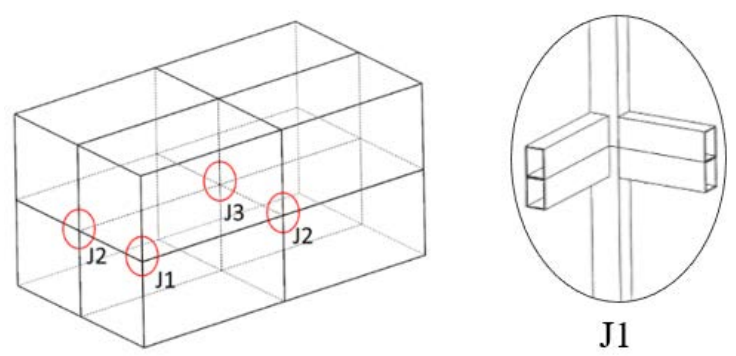

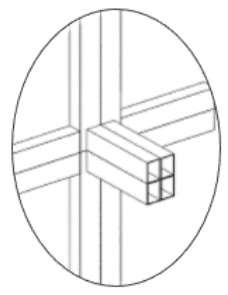

$\mathrm{J} 2$

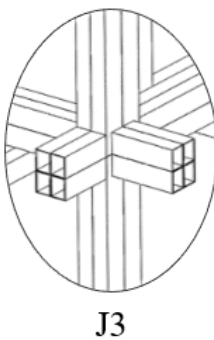

$\mathrm{J} 3$
Fig. 6. Assembled modular steel frame.

Steel PPVC units typically are designed to be abutting the core wall. In other words, public spaces (corridors) are included in steel modules which have lighter weight and can span up to 16 $m$ subject to regulation of road transportation. With this advantage, core wall and foundations can be constructed first while steel modules are being manufactured in the factory. The speed of construction is much faster than the system where cast in-situ corridors are used.

Using pure steel modules in high-rise PPVC system will make the column sizes to be large or thicker steel section, and thus will lead to higher costs and less usable space. For example, in the world's tallest PPVC building, a 32-story braced steel PPVC systems (B2 Tower) in New York, column sizes were kept to be $150 \times 150 \mathrm{~mm}$ but the thickness of steel was up to $38 \mathrm{~mm}$ [8]. Variations of column sizes along the height of PPVC buildings will also lead to difficulties in module-to-module connections. Thus, using composite column design by keeping the column sizes while changing the infill concrete grades can be an ideal solution.

A joining technique (bolted beam-beam connection) that joins the floor beams of the upper module and ceiling beams of the lower module using bolted connection, as shown in Fig. 7, has been studied by many researchers and designers over the world. According to Chen et. al [9] and Lee et. al [10], bolted beam-beam connections can be used in steel PPVC structures and can be designed to be ductile and strong enough to resist seismic loadings. However, this connection is very stringent on manufacturing tolerances. Large number of bolts usually leads to challenges in bolting. In addition, to perform bolted connections, entering the prefinished modules and access holes on walls, floors or ceilings are necessary at every corner of the modules. This will cause potential damages to internal finishes and costly rework on site. Moreover, in Singapore, $100 \%$ wall finishes are required [3]. Therefore, bolted beam-beam connection may not be idealised for steel PPVC structures in Singapore.

To solve the above issues, another type of joining technique that allows for connections to be made outside the modules. It typically utilizes threaded bars (or reinforcements) to connect the columns together as shown in Fig. 8. However, there are also several problems. Firstly when each column is connected vertically through more than one threaded bars, installation becomes very difficult since there are at least four columns of one module. Secondly, if only one threaded bar is to be used, the axial and moment resistance of such connection is very low [11]. As a result of this, the frame action will be weak and lateral deflection of the global system will be large and thus not suitable for high-rise building. 

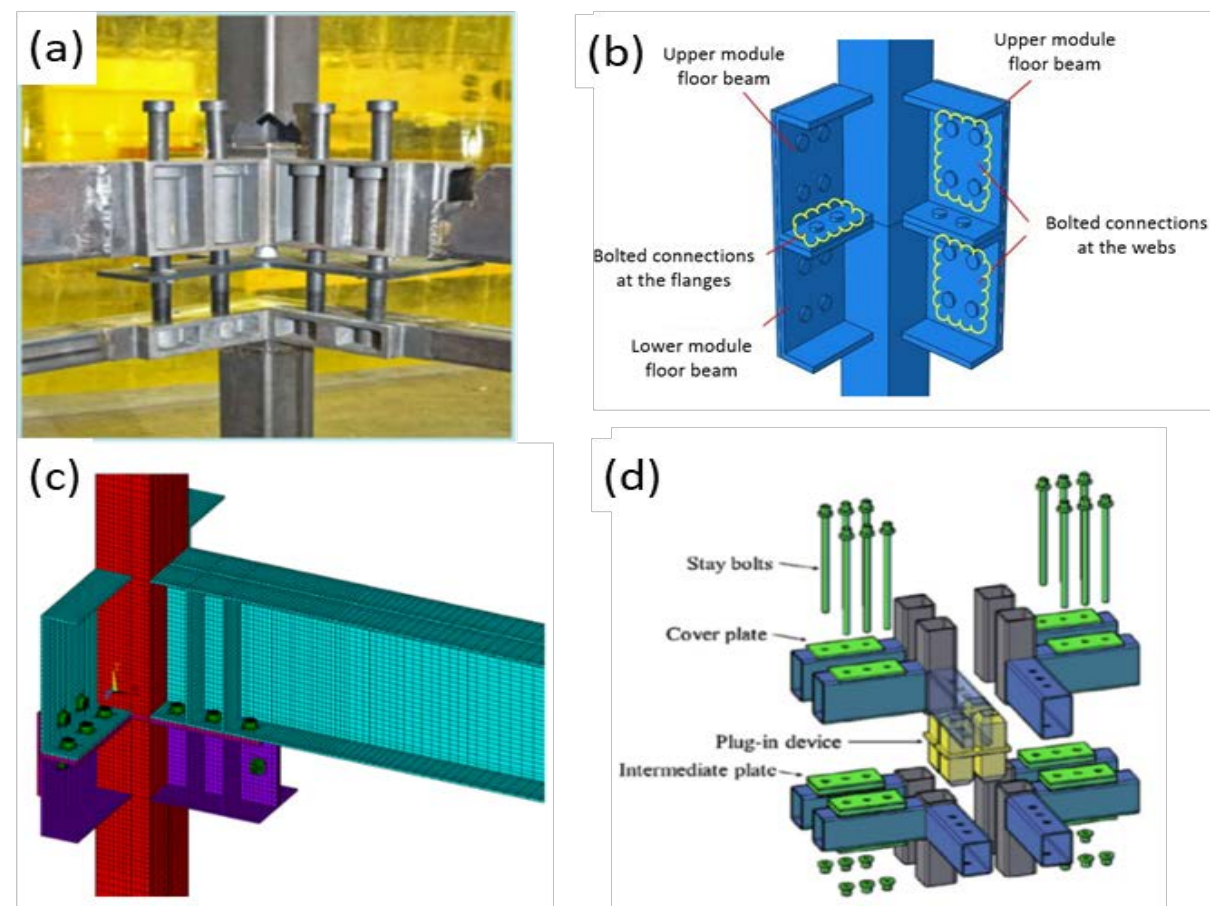

Fig. 7. Typical beam-beam connection (a) VectorBloc System (Bowron, 2016), (b) Corner Joint J1 (Mao, 2017), (c) Perimeter Joint J2 (Lee et al., 2017), and (d) Interior Joint J3 (Chen et al., 2017).

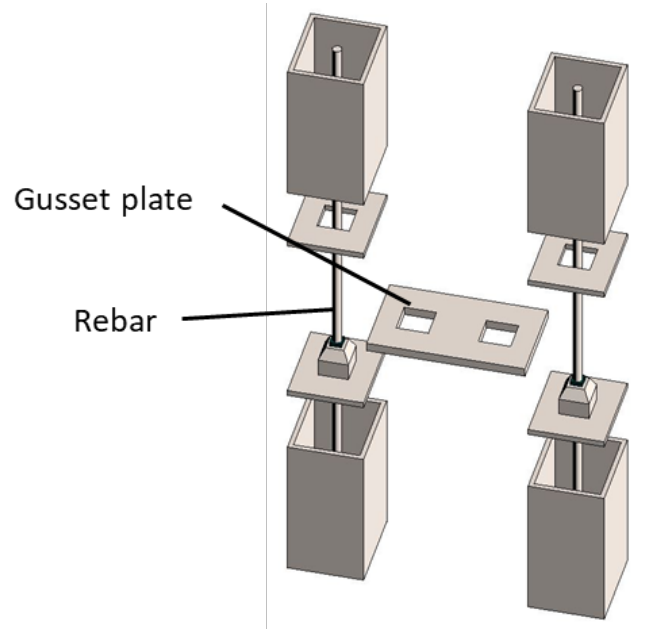

Fig. 8. Module-to-module connection using single rebar.

In summary, for high-rise steel PPVC system, there has not been a good joining technique that can allow for ease of installation and can yet provide high structural resistance. A new joining technique shall be developed to tackle such issues. In addition, it has been concluded by many researchers that most PPVC joining module-to-module connections are semi-rigid $[9,10,12]$. How will the semi-rigidity affect the global performances of the structure should be studied.

\subsection{Automation technologies}

At current practice, the productivity and efficiency of PPVC are not fully maximized yet because there are still many manual labour work involved in the factory as well as at construction site. This is because the initial investment cost in automation technologies is too high and the support from local authority is lacking. The manufacturing of modular unit in factory are sometimes still involved conventional panelized casting, followed by assembly of panels into modular unit. This causes error in verticality and horizontality of the module as well as water leakage problem. These problems will lead to many problems during on-site assembly. On the other hand, due to lack of automated machines at construction site, longer time is required to adjust the lifting chains such that the modules is stable before assembly. Poor design of lifting frame that leads to unstable module as displayed in Fig. 9 during lifting might causes damage of internal finishes of modules especially in PPVC whereby the modules are completed with finishes. This is also caused by many lifting chains in the lifting frame, as depicted in Fig. 10, and all the chains are adjusted manually. Furthermore, at current practice, the locating of module during assembly is still conducted manually as displayed in Fig. 11. 


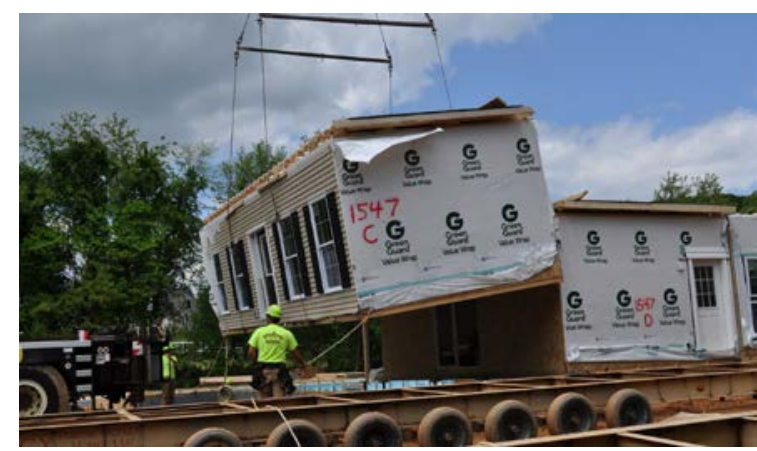

Fig. 9. Unstable module during assembly [13].

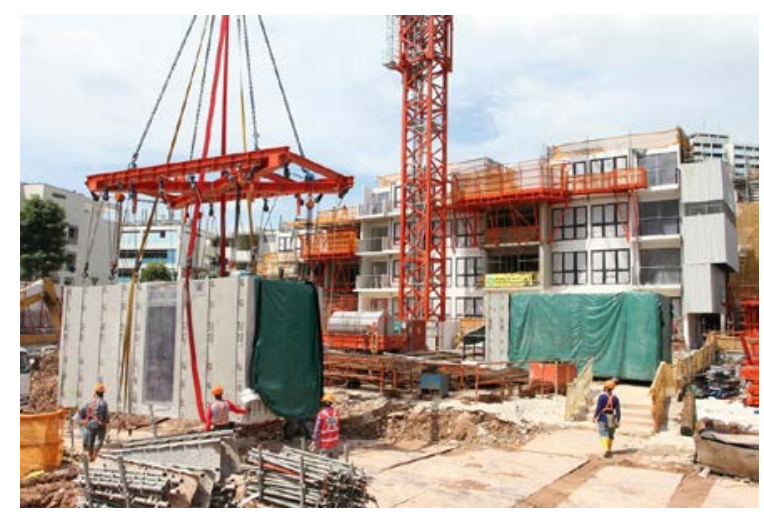

Fig. 10. Lifting of concrete PPVC module [14].

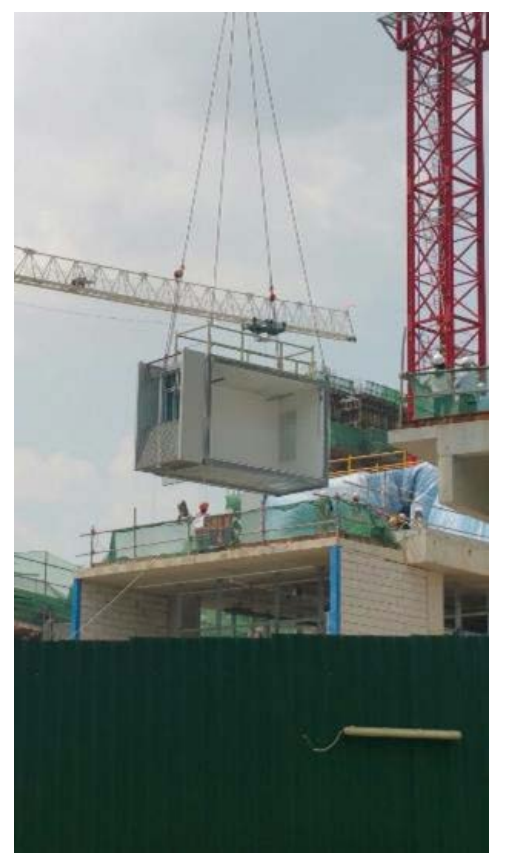

Fig. 11. Locating the module.

Nonetheless, it is expected that conventional cast in-situ method will be increasingly being replaced with modular construction, where building components such as columns, slabs and even larger volumetric elements like entire rooms are manufactured off-site in controlled environment. Like other industries, automation is becoming more widespread in construction. Not only are highly automated equipment used in factories to manufacture building components faster and with a better quality control, works on site are also moving towards a greater degree of mechanization such as using machineries for interior fit-out in factory as shown in Fig. 12. Highly automated casting machine as depicted in Fig. 13 increases the productivity and quality in manufacturing the building component. It is believed that $3 \mathrm{D}$ printing of a whole modular unit should be the future goal of modular construction. In addition, 3D laser scanner can be used to auto-scan the whole unit in factory and also after on-site installation to measure the verticality and horizontality of the modules, providing quick and accurate measurement.

In application to asset and inventory management, RFID system consists of a reader (scanner) and a tag with embedded chip and antenna. When tag appears in the reader's working range (around 60 feet), it "wakes up" and sends a signal containing encoded information. The reader receives and decodes information, and sends it to the inventory and asset management software for processing. RFID provides tremendous increase in processing speed as compared to traditional barcode scanning. Instead of scanning one item at a time, with RFID technology you can read information from all items in the working radius at the same time. For example, if you need to check in inventory on a service van, all you need to do is turn on RFID reader and information for all inventory in the van will be read and transmitted to an asset and inventory management software in a matter of seconds.

Furthermore, using BIM and other technologies, communication and decision making among architects, engineers, contractors, and building owners can be streamlined across all functional areas. The implementation augmented reality (AR) and virtual reality (VR) can further enhance the BIM models. With these technologies, project parties can experience a virtual walkthrough of a building even before it is constructed so that potential issues and problems can be identified and solved before actual construction. Advances in technology have also enabled BIM models to be accessed on site through cloud-connected mobile devices that all real-time sharing for efficient decision making. Lastly, with all the building information 
input in BIM models, the model can also be used to calculate the centre of gravity of each module, incorporating with auto-calibrated lifting frame, to stabilize the module during lifting in a quicker and easier way as well as minimizing the damage of the modules.

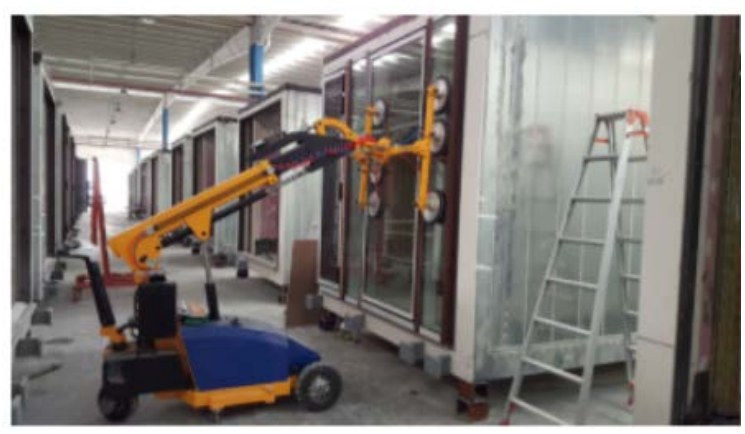

Fig. 12. Interior fit-out in factory [15].

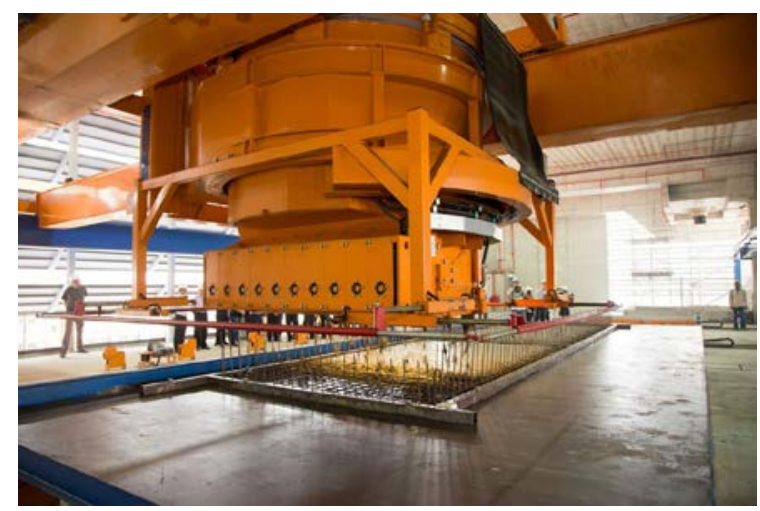

Fig. 13. Highly automated equipment is used in Singapore's Integrated and Prefabrication Hubs to manufacture building components [14].

\section{Conclusion}

Modular construction shows great potential in improving construction productivity and efficiency. Despite of the challenges in implementing this technology, several options are discussed as solution of these issues. It is believed that modular construction will shape the future construction industry.

\section{Acknowledgement}

The authors would like to acknowledge the financial support by the National Research Foundation (NRF) and SembCorp-NUS Corp Lab under project grant R-261-513-009-281.

\section{References}

[1] Construction Industry Development Board [CIDB]. Raising Singapore's Construction; 1992.

$$
\text { Retrieved }
$$

from
https://www.bca.gov.sg/publications/Buildabilit ySeries/others/rscp_intr2.PDF

[2] Mills S, Grove D, Egan M. Breaking the prefabricated ceiling: challenging the limits for modular high-rise. CTBUH Conference Proceedings; 2015.

[3] Building and Construction Authority. Code of Practice on building design/buildability; 2017. Retrieved

from: https://www.bca.gov.sg/BuildableDesign/others/ cop2017.pdf.

[4] Liew JYR, Dai Z, Wang Y. Prefabricated prefinished volumetric construction in high-rise buildings. 11th Pacific Structural Steel Conference Proceedings; 2016.

[5] Dang DH. Design optimization for prefabricated pre-finished volumetric construction. Final Year Project Thesis, National University of Singapore; 2016.

[6] Liew JYR, Xiong M, Xiong D. Design of High Strength Concrete Filled Tubular Columns For Tall. International Journal of High-rise Building 2014;3.

[7] Kurobane Y. Design guide for structural hollow section column connections. Verlag TUV Rheinland; 2004.

[8] Farnsworth D. Modular tall building design at Atlantic Yards B2. CTBUH Conference Proceedings; 2014.

[9] Chen Z, Liu J, Yu Y. Experimental study on interior connections in modular steel buildings. Engineering Structures 2017;147:625-638.

[10] Lee JH, Won DH, Jeong YJ, Kim SH, Kang YJ. Interfacial Shear Behavior of a High-Strength Pile to Sleeve Grouted Connection. Engineering Structures 2017;151:704-23.

[11]Pang, SD, Liew JYR, Dai Z, Wang Y. Prefabricated prefinished volumetric construction joining techniques review. Modular and Offsite Construction Summit Proceedings; 2016.

[12] Cao K, Li GQ, Lu Y. Stability analysis of nonsway modular frame with semi-rigid connection. Journal of Architecture and Civil Engineering $2017 ; 33$.

[13] Semler K;2017. Retrieved from https://www.linkedin.com/pulse/settingexpectations-modular-home-installation-kensemler-caps.

[14]Carlisle P; 2017. Retrieved from http://www.thailand-construction.com/debutfor-two-liebherr-high-top-tower-cranes-onworlds-tallest-concrete-module-structure-insingapore/.

[15]Buildtech Asia; 2017. Retrieved from http://www.buildtechasia.com/5-technologieschanging-way-we-build-asia-1. 